\title{
Accuracy of ultrasound, clinical and maternal estimates of birth weight in term women
}

\author{
T. Ashrafganjooei, ${ }^{1}$ T. Naderi, ${ }^{2}$ B. Eshrati ${ }^{3}$ and N. Babapoor ${ }^{2}$
}

$$
\begin{aligned}
& \text { دقة التقدير ات بالموجات فوق الصوتية والتقديرات السريرية (الإكلينيكية)، وتقدير ات الأمهات لوزن ولدانهن في تمام الحمل } \\
& \text { طاهرة أشر فكنجويي، طيبه نادري، بابك عشرتي، نوشئ فورين بابابور }
\end{aligned}
$$

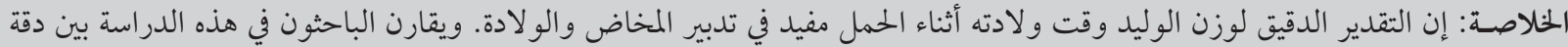

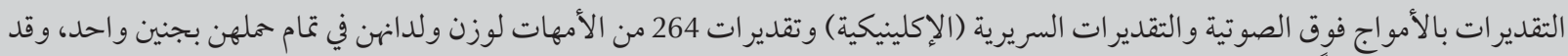

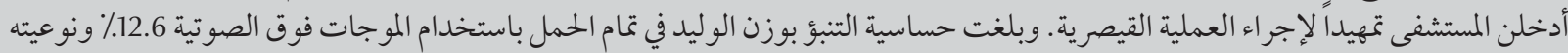

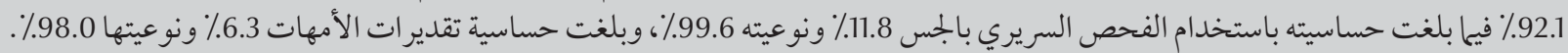

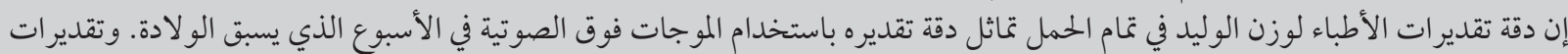

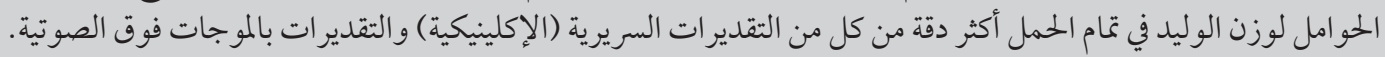

ABSTRACT Accurate prenatal estimation of birth weight is useful in the management of labour and delivery. This study compared the accuracy of ultrasound, clinical and maternal estimates of fetal weight in 246 parous women with singleton, term pregnancies admitted for scheduled caesarean section. The sensitivity and specificity of predicting birth weight by ultrasound measures were $12.6 \%$ and $92.1 \%$, by clinical palpation were $11.8 \%$ and $99.6 \%$ and by maternal estimate were $6.3 \%$ and $98.0 \%$ respectively. Clinicians' estimates of birth weight in term pregnancy were as accurate as routine ultrasound estimation in the week before delivery. Parous women's estimates of birth weight were more accurate than either clinical or ultrasound estimation.

Précision de l'estimation échographique, clinique et maternelle du poids du bébé à la naissance chez des femmes enceintes à terme

RÉSUMÉ L'estimation anténatale du poids à la naissance est utile au niveau de la gestion du travail et de l'accouchement. Cette étude a comparé la précision de l'estimation échographique, clinique et maternelle du poids du fotus chez 246 femmes pares, enceintes d'un seul enfant, et ayant mené leur grossesse à terme, admises pour une césarienne programmée. La sensibilité et la spécificité de la prédiction du poids à la naissance au moyen de l'échographie étaient de 12,6 \% et 92,1 \% respectivement, alors qu'elles étaient de 11,8 \% et 99,6\% pour la palpation clinique et de $6,3 \%$ et 98,0\% pour l'estimation maternelle. Pour les grossesses à terme, les estimations du poids à la naissance par les cliniciens étaient aussi précises que les estimations échographiques habituellement réalisées la semaine avant l'accouchement. Les estimations des femmes pares étaient plus précises que celles des cliniciens et de l'échographie.

${ }^{7}$ Department of Gynaecologic Oncology; ${ }^{2}$ Department of Obstetrics and Gynaecology, Kerman University of Medical Sciences, Kerman, Islamic Republic of Iran (Correspondence to T. Ashrafganjooei: tganjoei@yahoo.com).

${ }^{3}$ Faculty of Paramedical Sciences, Arak University of Medical Sciences, Arak, Islamic Republic of Iran.

Received: 17/08/07; accepted: 04/03/08 


\section{Introduction}

Accurate prenatal estimation of fetal weight (EFW) in late pregnancy and labour is extremely useful in the management of labour and delivery, permitting obstetricians to make decisions about instrumental vaginal delivery, trial of labour after caesarean delivery and elective caesarean section for patients suspected of having a macrosomic fetus [1-5]. An accurate diagnosis of macrosomia for patients with gestational diabetes can reduce perinatal morbidity as it may assist the physician and staff in deciding the appropriate route of delivery to prepare for shoulder dystocia or to prevent a traumatic injury [6]. Correct EFW values are also important when intrauterine growth is restricted and in preterm labour $[7,8]$.

EFW can be done by mothers (if they are parous), by clinicians using Leopold manoeuvres or by ultrasound. In the 1970s, the use of ultrasound to estimate fetal weight gained popularity because of the perceived ability to standardize and reproduce measurements $[3,9]$, although the technique can be challenging, depending on the mother's physique, uterine anomalies or amniotic fluid index [10]. Clinical EFW has been shown to accurately predict birth weight. For example, Baum et al. showed no significant difference between clinical and sonographic estimates of fetal weight; $64.0 \%$ versus $62.5 \%$ of the estimates respectively were within $10 \%$ of the actual birth weight [1]. Maternal EFW is comparable to both clinical or ultrasound predictions in both term and postdate babies $[11,12]$. Some researchers concluded that clinical EFW has higher accuracy than ultrasound EFW $[2,13]$, but other studies showed that ultrasound EFW is more accurate [14] and Chauhan et al. showed that the accuracies of both methods are the same [15].

Due to difficulties in accessing ultrasound equipment in rural areas of the Islamic Republic of Iran, this study aimed to evaluate the benefits of ultrasound EFW by comparing the accuracy of maternal, clinical and ultrasound EFW in term women. In addition, we sought to evaluate potential variables that may affect the accuracy of the EFW during labour.

\section{Methods}

Between July 2002 and December 2004, this prospective study evaluated 3 different methods of EFW - clinical, maternal and ultrasound measurements-on 246 parous women admitted for scheduled caesarean section within 1 week of delivery in the hospital of Kerman University of Medical Sciences, Kerman, Islamic Republic of Iran. The sample size was calculated to estimate a sensitivity and specificity of $80 \%$ with a precision of $5 \%$. The inclusion criteria were: singleton pregnancy and live-born infant without congenital malformations or hydrops fetalis.

The mothers were instructed about the purpose of the study and gave informed consent for participation. Approval for the study was obtained from the research ethical committee of the University.

Ultrasound EFW was obtained for all women by the same physician with a 3.5 MHz transducer (Hitachi EUB-500, Tokyo, Japan) using standard Hadlock reference tables that used biparietal diameter, abdominal circumference and femur length for calculating fetal weight. The physician performing the ultrasound was unaware of the 2 other estimations. ClinicalEFW was obtained on the day of operation by palpation using Leopold manoeuvres. A total of 3 physicians ( 2 obstetricians and 1 senior resident) examined every woman and we took an average of the 3 estimates. All were unaware of the other clinical and ultrasound EFWs. Maternal EFW was obtained by asking mothers, who were all parous, to estimate the weight of their baby. The 3 estimates of fetal weight, patient demographic data and actual birth weight were recorded on data sheets that were kept separate from the patient's chart.

Neonatal birth weight was considered as the gold standard. Correlations were made of the actual birth weight with the ultrasound, clinical and maternal EFW independently. We also calculated the sensitivity, specificity and positive and negative predictive values for the ultrasound, clinical and maternal EFW compared with actual birth weight. Normal birth weight was considered as 2500-4000 g. We used ROC curve with the chi-squared test to compare the accuracy of different methods of estimation of fetal weight. A $P$-value of $<0.05$ was considered statistically significant. Data were analysed using Medcalc, version 7.4.4.1 and Stata, version 8 software.

\section{Results}

A total of 246 mothers participated in the study. The mean maternal age was 27.6 [standard deviation (SD) 5.4] years and mean parity was 1.2 (SD 1.2). The mean actual birth weight was 3339 (SD 443) g, while the mean estimated fetal weights by ultrasound, clinical assessment and maternal report were 3305 (SD 335)g, 3321 (SD 449) gand 3158 (SD 463) g respectively.

For the clinical EFW, there was no statistically significant difference in the mean estimates comparing the 3 physicians with different years of experience: obstetrician with 14 years' experience [3316 (SD 355) g, range 2500-4200], obstetrician with 13 years' experience [3319 (SD 343) g, range 2000-4200g] or senior resident with 3 years' experience[3327 (SD 378) g, 2500-4800 g].

The sensitivity values of predicting birth weights for ultrasound, clinical and maternal EFW were $17.6 \%, 11.8 \%$ and $6.3 \%$, with specificity of $93.5 \%, 99.6 \%$ and $98.0 \%$, respectively (Table 1). 


\begin{tabular}{|c|c|c|c|c|c|c|c|}
\hline \multirow[t]{3}{*}{ Method of estimation } & \multicolumn{2}{|c|}{ Normal weight children ${ }^{a}$} & \multicolumn{2}{|c|}{ Abnormal weight children } & \multirow[t]{2}{*}{ Sensitivity } & \multirow[t]{2}{*}{ Specificity } & \multirow{2}{*}{$\begin{array}{l}\text { Positive } \\
\text { predictive } \\
\text { value }\end{array}$} \\
\hline & $\begin{array}{l}\text { Correctly } \\
\text { estimated }\end{array}$ & $\begin{array}{l}\text { Incorrectly } \\
\text { estimated }\end{array}$ & $\begin{array}{l}\text { Correctly } \\
\text { estimated }\end{array}$ & $\begin{array}{l}\text { Incorrectly } \\
\text { estimated }\end{array}$ & & & \\
\hline & No. & No. & No. & No. & $\%$ & $\%$ & $\%$ \\
\hline Ultrasound & 211 & 18 & 3 & 14 & 17.6 & 93.5 & 14.3 \\
\hline Clinical & 228 & 1 & 2 & 15 & 11.8 & 99.6 & 67.0 \\
\hline Maternal & 200 & 4 & 1 & 15 & 6.3 & 98.0 & 20.0 \\
\hline
\end{tabular}

${ }^{a}$ Normal birth weight was considered as 2500-4000 g.

Figure 1 shows the results of ROC curve analysis. Using the chi-squared test it was evident that the accuracy of the 3 tests were not significantly different from each other $(P=0.35)$. According to the maximum point of each curve of the 3 measures, a new cut-off point was used for each method of EFW and the sensitivity and specificity were estimated (Table 2).

\section{Discussion}

Birth weight is a key variable affecting fetal and neonatal morbidity, particularly in preterm and small-for-dates babies. In addition, it is of value in the management of breech presentations, diabetes mellitus, trial of labour, macrosomic fetuses and multiple births [16].
We found that clinicians' estimates of birth weight in term pregnancy were as accurate as routine ultrasound estimation in the week before delivery. Furthermore, parous women's estimates of birth weight were more accurate than either clinical or ultrasound estimation.

There have been differing results about the accuracy of the various methods of estimating fetal weight.

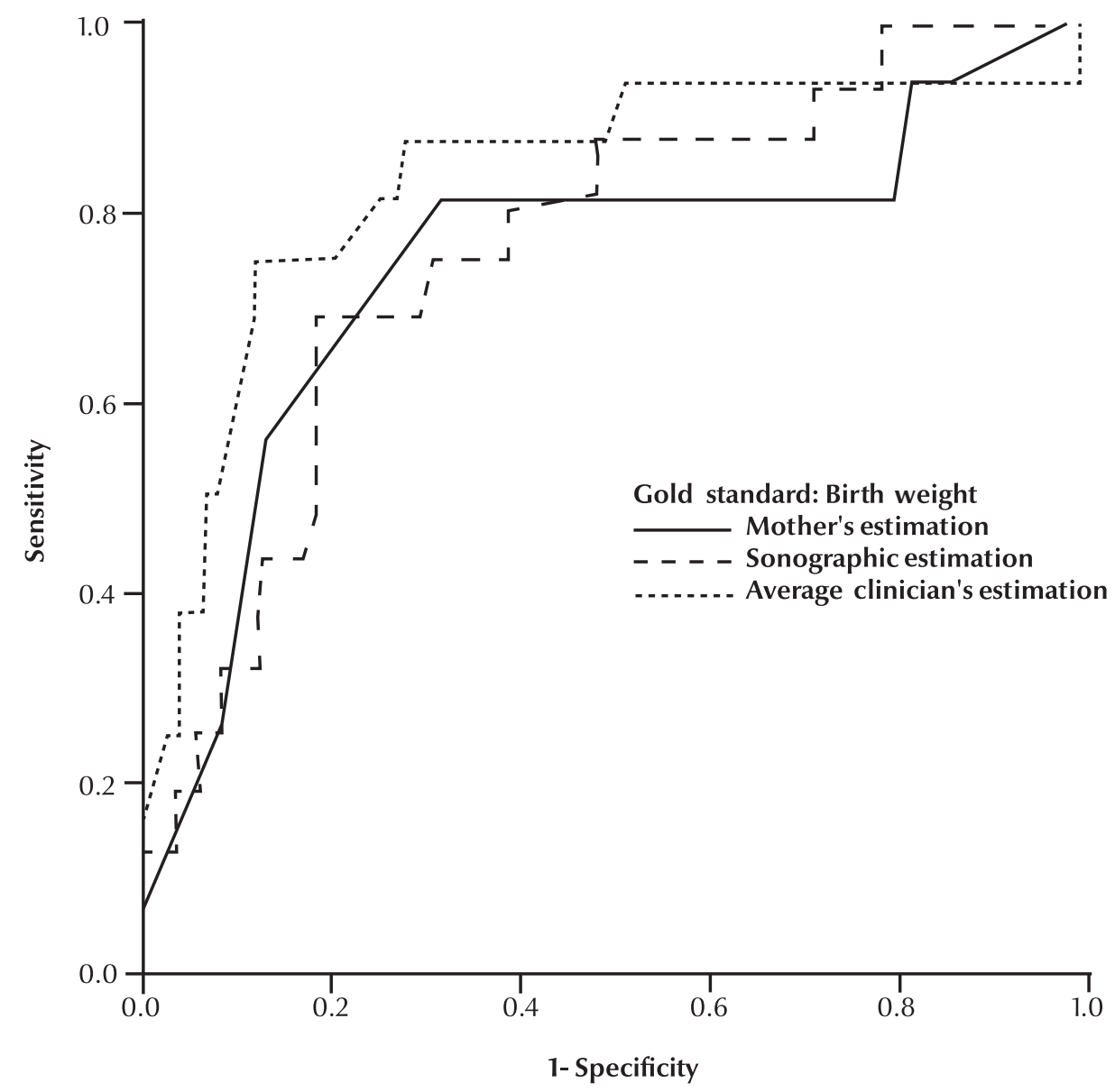

Figure 1 Receiver operating characteristic (ROC) curves for estimation of fetal weight 


\begin{tabular}{|c|c|c|c|c|}
\hline \multirow[t]{2}{*}{ Method of estimation } & $\begin{array}{l}\text { Cut-off point } \\
\text { for weight (g) }\end{array}$ & $\begin{array}{l}\text { Maximum } \\
\text { specificity }\end{array}$ & $\begin{array}{l}\text { Maximum } \\
\text { sensitivity }\end{array}$ & ROC area \\
\hline & & $\%$ & $\%$ & \\
\hline Ultrasound & 3625 & 62.5 & 81.7 & 0.76 \\
\hline Clinical & 3500 & 75.0 & 76.1 & 0.84 \\
\hline Maternal & 3400 & 62.5 & 69.5 & 0.75 \\
\hline
\end{tabular}

Clinical estimation of fetal weight using abdominal palpation has been shown to be accurate to within $500 \mathrm{~g}$ in $85 \%$ of cases, with more accuracy in the average, term fetus than in the preterm and macrosomic fetus [17-20]. Diase and Monga showed that in diabetic women, neither parity nor maternal weight affected the accuracy of any of the birth weight estimates [6]. Humphries et al. showed that the accuracies of birth weight estimation, both clinical and ultrasound, were still relatively low [16]. Some studies showed the ultrasound EFW was the best method for EFW, especially in preterm fetuses $[2,12,21,22]$, but other studies, such as ours, did not conclude any difference between these methods $[1,13,14,23,24]$. Other studies have reported limited accuracy of ultrasound EFW at term, particularly in macrosomic fetuses $[25,26]$.

The advantage of using ultrasound for EFW has been questioned. Baum et al. concluded that ultrasound offered no advantage over clinical estimates of fetal weight at term [1]. Mother's estimates should be viewed as equally valid as clinical estimates, especially in the light of the need for realistic, achievable standards. They also reported that senior resident clinical estimates were superior to this research, we found that the accuregardless of their length of experience, which agrees with Ben-Aroya et al. [7]. Two studies reported no difference in the accuracy of EFWs by physician's palpation versus maternal estimation to junior resident estimates. In contrast racy of physicians' estimates was similar
$[11,12]$, whereas others showed that clinical and ultrasound EFW were more accurate than maternal EFW [20]. In our study we found, as previously reported by O'Reilly-Green and Divon [27], that mother's EFW was the best method of fetal weight screening.

The major strength of our study, in contrast to similar studies, is that the number of patients was sufficient to ensure statistical validity of the finding of no difference between methods of EFW.

\section{Conclusion}

Our results are supported by previous studies that indicate that ultrasound EFW offers no advantage over clinician's EFW when performed during late pregnancy or labour. An EFW should be recorded in the assessment of all patients who are at term and again when they are in labour, with full awareness of the limitations of the methods for making such estimates. This study and others show that parous mother's estimates of fetal weight are accurate and should be given due consideration.

\section{References}

1. Baum JD, Gussman D, Wirth III JC. Clinical and patient estimation of fetal weight vs. ultrasound estimation. Obstetrical and gynecological survey, 2002, 57(9):558-9.

2. Chauhan SP et al. Limitations of clinical and sonographic estimates of birth weight: experience with 1,034 parturients. Obstetrics and gynecology, 1998, 91:72-7.

3. Kurmanavicius J et al. Ultrasonographic fetal weight estimation: accuracy of formulas and accuracy of examiners by birth weight from 500 to $5000 \mathrm{~g}$. Journal of perinatal medicine, 2004, 32:155-61.

4. Ben-Haroush A et al. Accuracy of sonographically estimated fetal weight in 840 women with different pregnancy complications prior to induction of labor. Ultrasound in obstetrics and gynecology, 2004, 23(2):172-6.

5. Mclntire DD et al. Birth weight in relation to morbidity and mortality among newborn infants. New England journal of medicine, 1999, 340(16):1234-8.

6. Diase K, Monga M. Maternal estimates of neonatal birth weight in diabetic patients. Southern medical journal, 2002, 95(1):92-4.
7. Ben-Aroya $Z$ et al. Effect of ob/gyn residents' fatigue and training level on the accuracy of fetal weight estimation. Fetal diagnosis and therapy, 2002, 17:177-81.

8. Ott WJ. Sonographic diagnosis of fetal growth restriction. Clinical obstetrics and gynecology, 2006, 49(2):295-07.

9. Ratanasiri T et al. Comparison of the accuracy of ultrasonic fetal weight estimation by using the various equations. Journal of the Medical Association of Thailand, 2002, 85:962-7.

10. Alsulyman OM, Ouzounian JG, Kjos SL. The accuracy of intrapartum ultrasonographic fetal weight estimation in diabetic pregnancies. American journal of obstetrics and gynecology, 1997, 177:503-6.

11. Chauhan SP et al. Clinical estimate of birth-weight in labour: factors influencing its accuracy. Australian and New Zealand journal of obstetrics and gynaecology, 1993, 33(4):371-3.

12. Chauhan SP et al. Intrapartum clinical, sonographic and parous patients' estimates of newborn birth weight. Obstetrics and gynecology, 1992, 79:956-8.

13. Chauhan SP et al. Parous patients' estimate of birth weight in postterm pregnancy. Journal of perinatology, 1995, 15:192-4. 
14. Chauhan SP et al. Intrapartum prediction of birth weight: clinical versus sonographic estimation based on femur length alone. Journal of obstetrics and gynaecology, 1993, 81(51):695-7.

15. Baum JD, Gussman D, Wirth JC 3rd. Clinical and patient estimation of fetal weight vs. ultrasound estimation. Journal of reproductive medicine, 2002, 47(3):194-8.

16. Chauhan SP et al. Intrapartum detection of a macrosomic fetus: clinical versus and sonographic models. Australian \& New Zea land journal of obstetrics and gynaecology, 1995, 35:266-70.

17. Humphries J et al. Sonographic estimate of birth weight: relative accuracy of sonographers versus maternal-fetal medicine specialists. Journal of maternal-fetal and neonatal medicine, 2002, 11:108-12.

18. Chauhan $\mathrm{S}$ et al. Estimate of birth weight among post-term pregnancy: clinical versus sonographic. Journal of maternalfetal and neonatal medicine, 1994, 3:208-11.

19. Hirata $G$ et al. Ultrasonographic estimation of fetal weight in the clinically macrosomic fetus. American journal of obstetrics and gynecology, 1990, 162:238.

20. Patterson R. Estimation of fetal weight during labor. Obstetrics and gynecology, 1985, 65:330-2.
21. Sherman DJ et al. A comparison of clinical and ultrasonic estimation of fetal weight. Obstetrics and gynecology, 1998, 91:212-7.

22. Zayed F, Abu-Heija A. A comparison between ultrasound and clinical methods for predicting fetal weight. Journal of obstetrics and gynaecology, 1999, 19(2):159-61.

23. Sacks DA, Chen W. Estimating fetal weight in the management of macrosomia. Obstetrical and gynecological survey, 2000, 55(4):229-39.

24. Nahum GG, Stanislaw H. Ultrasonographic prediction of term birth weight: How accurate is it? American journal of obstetrics and gynecology, 2003, 188:566-74.

25. Ramon $\mathrm{S}$ et al. Clinical versus ultrasound estimation of fetal weight. Australian and New Zealand journal of obstetrics and gynaecology, 1992, 32(3):196-9.

26. Sherman DJ et al. A comparison of clinical and ultrasound estimation of fetal weight. Obstetrics and gynecology, 1998, 91(2):12-7.

27. O'Reilly-Green C, Divon M. Sonographic and clinical methods in the diagnosis of macrosomia. Clinical obstetrics and gynecology, 2000, 43(2):309-20

\section{Women and health: today's evidence tomorrow's agenda}

This WHO report provides the latest and most comprehensive evidence available to date on women's specific needs and health challenges over their entire life-course.

Women's health has long been a concern for WHO but today it has become an urgent priority. This report explains why. Using current data, it takes stock of what we know now about the health of women throughout their lives and across the different regions of the world. Highlighting key issues - some of which are familiar, others that merit far greater attention - the report identifies opportunities for making more rapid progress. It points to areas in which better information - plus policy dialogue at national, regional and international levels - could lead to more effective approaches.

Further information about this and other WHO publications can be found at: http://www.who.int/publications/en/ 